\title{
Feasibility and safety of airway bypass stent placement and influence of topical mitomycin C on stent patency
}

\author{
Cliff K. Choong, FRACS \\ Fabio J. Haddad, MD \\ Elaine Y. Gee, BS \\ Joel D. Cooper, MD
}

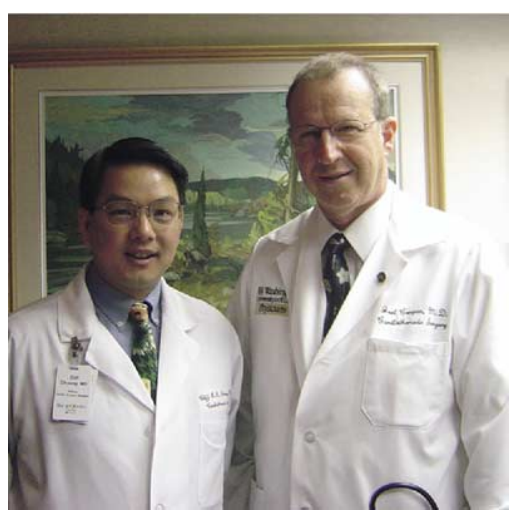

Drs Choong and Cooper
From the Department of Surgery, Division of Cardiothoracic Surgery, Washington University School of Medicine, BarnesJewish Hospital, St Louis, Mo.

Supported in part by Broncus Technologies, Inc (Mountain View, Calif), the Jacqueline Maritz Lung Center at Barnes-Jewish Hospital (St Louis, Mo), and National Institutes of Health grant RO1 HL 6219404. Dr Cooper acts as a consultant for Broncus Technologies, Inc.

Read at the Eighty-fourth Annual Meeting of The American Association for Thoracic Surgery, Toronto, Ontario, Canada, April 25-28, 2004.

Received for publication April 26, 2004; revisions received July 13 , 2004; accepted for publication July 21, 2004.

Address for reprints: Joel D. Cooper, MD, Division of Cardiothoracic Surgery, Washington University School of Medicine, One Barnes-Jewish Hospital Plaza, 3108 Queeny Tower, St Louis, MO 63110 (Email: cooperjd@msnotes.wustl.edu).

J Thorac Cardiovasc Surg 2005;129:632-8 $0022-5223 / \$ 30.00$

Copyright $\odot 2005$ by The American Association for Thoracic Surgery

doi:10.1016/j.jtcvs.2004.07.062
Objective: Airway bypass via transbronchial fenestration has been shown to improve forced expiratory volume and flow in explanted human emphysematous lungs. The aim of this study was to evaluate the feasibility and safety of in vivo airway bypass stent placement by using a canine model and to assess the influence of topical mitomycin $\mathrm{C}$ on the prolongation of stent patency.

Methods: With dogs under general anesthesia, suitable segmental and subsegmental bronchial wall sites were selected by direct visualization with a flexible bronchoscope. Peribronchial blood vessel injury was avoided by using a Doppler probe. Transbronchial fenestration was formed with a 22-gauge transbronchial needle, and the passage was then dilated with a $2.5-\mathrm{mm}$ angioplasty balloon. A balloon expandable stainless-steel stent ( $3 \mathrm{~mm}$ long $\times 3 \mathrm{~mm}$ wide) with a sleeve of silicone rubber covering was placed within the fenestration. Animals were bronchoscoped weekly to assess stent patency. Seventy stents were placed in 12 dogs. Thirty-five served as controls, and the other 35 received transbronchoscopic topical application of mitomycin $\mathrm{C}$ once weekly to evaluate the effect on the maintenance of stent patency. Mitomycin $\mathrm{C}$ stents were divided into 4 groups according to the number of treatments: group A, 1 treatment only; group B, 4 weeks; group C, 7 weeks; and group D, 9 weeks. Each once-weekly mitomycin C application consisted of $0.2 \mathrm{~mL}$ at a concentration of $1 \mathrm{mg} / \mathrm{mL}$, delivered through a small polyethylene catheter.

Results: Four instances of minor and brief bleeding occurred during stent placement and resolved without incident. One pneumothorax occurred and was treated by chest tube placement, without any adverse sequelae. There was no mortality associated with stent placement. No delayed hemorrhage or pneumothorax occurred. All control stents were occluded at the 1-week follow-up. The median durations of stent patency for group A $(n=8)$, group $B(n=9)$, group $C(n=10)$, and group $D(n$ $=8$ ) were $3,8,13$, and greater than 20 weeks, respectively.

Conclusions: Airway bypass stent placement can be performed safely. In an animal model, most stents became occluded within 1 week, but topical mitomycin application resulted in significant prolongation of patency.

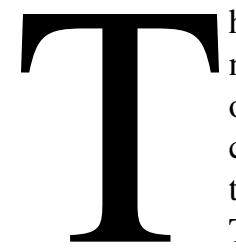

he ability of gas to move from one part of the lung to another through nonanatomic pathways is termed collateral ventilation and was first observed by Van Allen and colleagues ${ }^{1}$ in 1930. The importance of collateral ventilation is minimal in normal lungs because the resistance to air flow is higher in collateral channels than in the airway. ${ }^{2}$ The resistance of air flow in collateral channels is, however, low in patients with emphysema in comparison to that in healthy lungs. ${ }^{2,3}$ In emphysematous lungs, collateral ventilation provides important channels for gas distribution and may be therapeutically useful. ${ }^{4}$ Lausberg and colleagues ${ }^{5}$ have demonstrated 


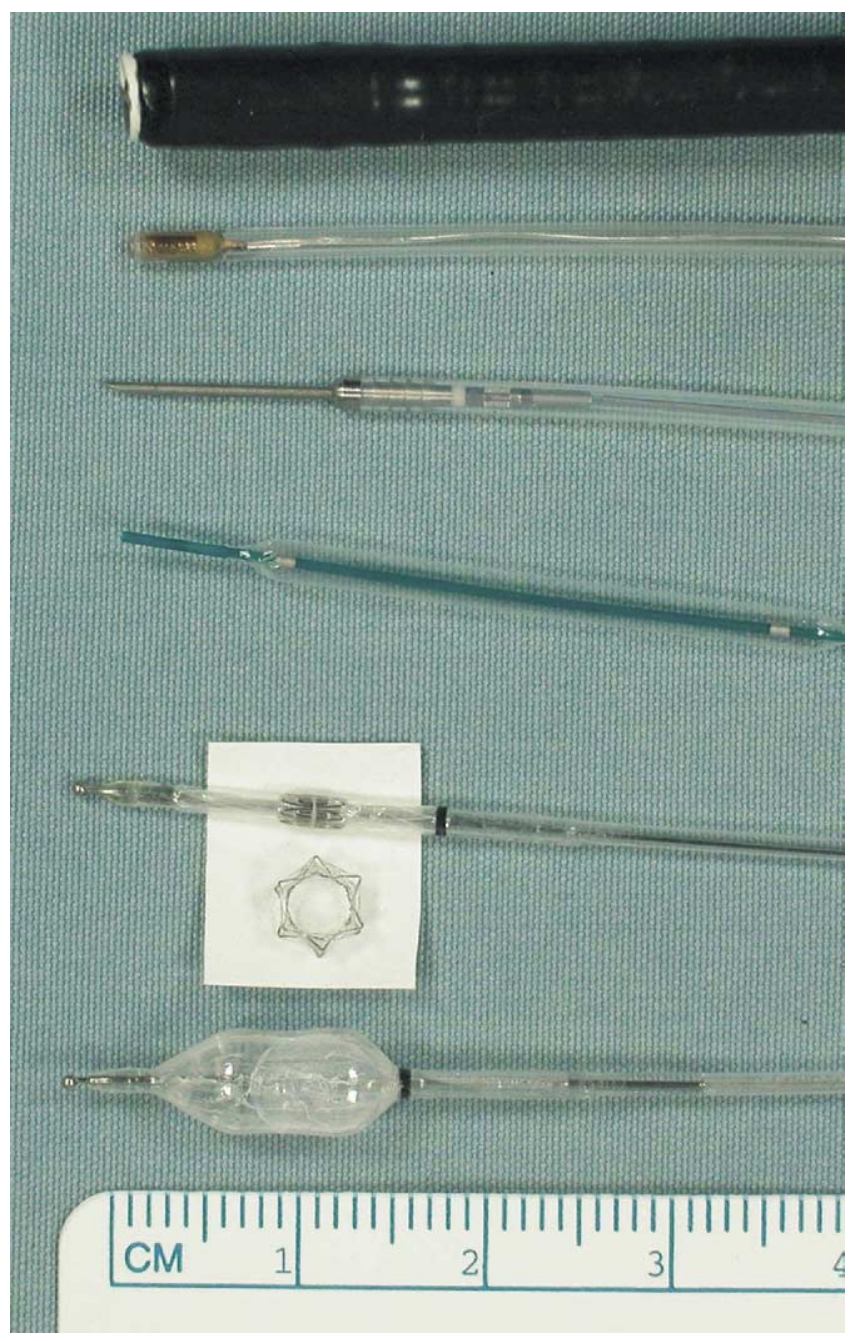

Figure 1. Equipment used in the procedure for airway bypass stent placement. From top to bottom: $4.9-\mathrm{mm}$ flexible bronchoscope, Doppler probe, 22-gauge transbronchial cytology needle, 2.5-mm angioplasty balloon, stent mounted on delivery device, expanded 3-mm $\times 3-\mathrm{mm}$ stent seen front on, and expanded balloon of the stent-delivery device.

that the creation of direct passages between emphysematous pulmonary parenchyma and bronchial airways (airway bypass) could take advantage of the extensive collateral ventilation present in emphysema to provide improvement in expiratory flow and volume, which is otherwise limited by the collapse of small peripheral airways during expiration. They reported an ex vivo study on 12 human emphysematous lungs and demonstrated improvement in forced expiratory volume in 1 second from an average of $245 \mathrm{~mL}$ at baseline to an average of $447 \mathrm{~mL}$ after the creation of 3 passages and to an average of $666 \mathrm{~mL}$ after the creation of 5 airway bypass passages.

These experimental results are promising and warrant further research to evaluate the feasibility and safety of the
TABLE 1. Mitomycin treatment groups

\begin{tabular}{clc}
\hline Group & \multicolumn{1}{c}{ Treatment duration* } & $\begin{array}{c}\text { No. } \\
\text { stents }\end{array}$ \\
\hline A & $\begin{array}{c}\text { Topical application at the time of } \\
\text { placement only } \\
\text { B }\end{array}$ & 8 \\
oplication at the time of placement and \\
once weekly for the next 3 \\
consecutive weeks (4 separate \\
applications) \\
Application at the time of placement and \\
once weekly for the next 6 \\
consecutive weeks (7 separate \\
applications)
\end{tabular}

*Each weekly topical application was $0.2 \mathrm{~mL}$ of $1 \mathrm{mg} / \mathrm{mL}$ mitomycin C.

airway bypass procedure in an in vivo setting. Preliminary experimental study in healthy dogs has shown that airway bypass stents occluded within a week after placement and this would pose a major problem for future potential clinical application. The topical application of mitomycin $\mathrm{C}$, an anti-inflammatory and antifibrotic agent, has been reported to be useful in the treatment of airway stenosis. ${ }^{6,7}$ The compound selectively inhibits DNA synthesis through mitomycin C-induced cross-linking, and this primarily occurs at guanine and cytosine. At sufficient drug concentrations, RNA and protein synthesis are also suppressed. ${ }^{7}$ These properties led to its use as an agent for reducing scar formation. This experimental study was undertaken to evaluate the feasibility and safety of airway bypass stent placement by using a canine model and to assess the influence of topical mitomycin $\mathrm{C}$ on stent patency.

\section{Methods}

Specially bred research mongrel dogs were used for the experiment. The dogs weighed 20 to $25 \mathrm{~kg}$. The airway bypass procedure was performed with dogs under general anesthesia, and they were mechanically ventilated via a single-lumen endotracheal tube. The equipment used is shown in Figure 1. A standard 4.9-mm external diameter flexible fiberoptic bronchoscope with a 2-mm working channel (BF-P160; Olympus American Inc, Melville, NY) was used to visualize the airway and to select appropriate target sites at the segmental or subsegmental bronchial level. A Doppler catheter (Broncus Technologies Inc, Mountain View, Calif) inserted through the bronchoscope channel was used to scan the target site and its adjacent area to detect and avoid peribronchial vessels before transbronchial fenestration. Once the appropriate site was identified, the Doppler probe was exchanged for a 22-gauge transbronchial needle (WANG transbronchial aspiration needle; CONMED Corporation, Utica, NY), and the needle was advanced through the bronchial wall to create a small passage into the lung 
TABLE 2. Summary of stent patency

\begin{tabular}{cccccc}
\hline Week & Control & Group A & Group B & Group C & Group D \\
\hline 1 & $0 / 35$ & $8 / 8$ & $9 / 9$ & $10 / 10$ & $8 / 8$ \\
2 & & $8 / 8$ & $9 / 9$ & $10 / 10$ & $7 / 8$ \\
3 & & $3 / 8$ & $8 / 9$ & $9 / 10$ & $7 / 8$ \\
4 & & $1 / 8$ & $8 / 9$ & $8 / 10$ & $6 / 8$ \\
5 & & $1 / 8$ & $8 / 9$ & $7 / 10$ & $6 / 8$ \\
6 & & $1 / 8$ & $5 / 9$ & $7 / 10$ & $6 / 8$ \\
7 & & $1 / 8$ & $5 / 9$ & $7 / 10$ & $6 / 8$ \\
8 & $1 / 8$ & $4 / 9$ & $7 / 10$ & $6 / 8$ \\
9 & $1 / 8$ & $4 / 9$ & $7 / 10$ & $6 / 8$ \\
10 & & $4 / 9$ & $7 / 10$ & $6 / 8$ \\
11 & & $1 / 8$ & $3 / 9$ & $7 / 10$ & $6 / 8$ \\
12 & & $1 / 8$ & $3 / 9$ & $6 / 10$ & $6 / 8$ \\
13 & $1 / 8$ & $2 / 9$ & $4 / 10$ & $6 / 8$ \\
14 & $1 / 8$ & $2 / 9$ & $4 / 10$ & $5 / 8$ \\
15 & $1 / 8$ & $2 / 9$ & $3 / 10$ & $5 / 8$ \\
16 & $1 / 8$ & $2 / 9$ & $3 / 10$ & $5 / 8$ \\
17 & $1 / 8$ & $2 / 9$ & $3 / 10$ & $5 / 8$ \\
18 & $1 / 8$ & $2 / 9$ & $3 / 10$ & $5 / 8$ \\
19 & $1 / 8$ & $2 / 9$ & $3 / 10$ & $5 / 8$ \\
20 & $1 / 8$ & $2 / 9$ & $3 / 10$ & $5 / 8$ \\
\hline
\end{tabular}

parenchyma. Aspiration through the needle was performed as it was slowly withdrawn out of the bronchial wall. The transbronchial needle had transparent tubing connected to it that provided visualization of the aspirated content. The target site was not used if blood was aspirated or if there was evidence of blood oozing out from the small hole created after the needle was withdrawn. An angioplasty catheter with an expandable balloon diameter of 2.5 $\mathrm{mm}$ and a length of $30 \mathrm{~mm}$ (Cordis Charger PTCA dilatation catheter; Cordis Corporation, Miami, Fla) was then inserted into the transbronchial fenestration and dilated to $2.5 \mathrm{~mm}$. A 3-mmlong $\times 3$-mm-wide balloon expandable stainless-steel stent covered with a sleeve of silicone rubber (Exhale stent; Broncus Technologies Inc., Mountain View, Calif) was then placed into the dilated transbronchial passage. The stent expands out on either end from its mid portion ( $3 \mathrm{~mm}$ wide) to a 5.5-mm flange, which helps to secure the stent (Figure 1). Control stents received $0.2 \mathrm{~mL}$ of topical normal saline at the time of placement via a delivery catheter passed through the working channel of the bronchoscope. Mitomycin C stents received a once-weekly topical application of $0.2 \mathrm{~mL}$ of mitomycin $\mathrm{C}$ (concentration $1 \mathrm{mg} / \mathrm{mL}$ ) delivered through the bronchoscope with the use of a delivery catheter. Seventy stents were placed in the airways of 12 dogs. Thirty-five stents acted as controls, and the other 35 stents were treated with topical mitomycin $\mathrm{C}$. The number of weekly mitomycin $\mathrm{C}$ treatments for each stent was determined by the protocol outlined in Table 1. All 12 dogs had control stents to allow for comparison of the mitomycin C-treated stents with the control stents in the same dog. The dogs were bronchoscoped weekly to assess stent patency and to allow for topical application of mitomycin $\mathrm{C}$. The stent was defined as occluded if there was tissue ingrowth to completely fill the inside channel of the stent for at least half of its length. The general health status of the dog was assessed by daily clinical examination and weekly complete blood count,

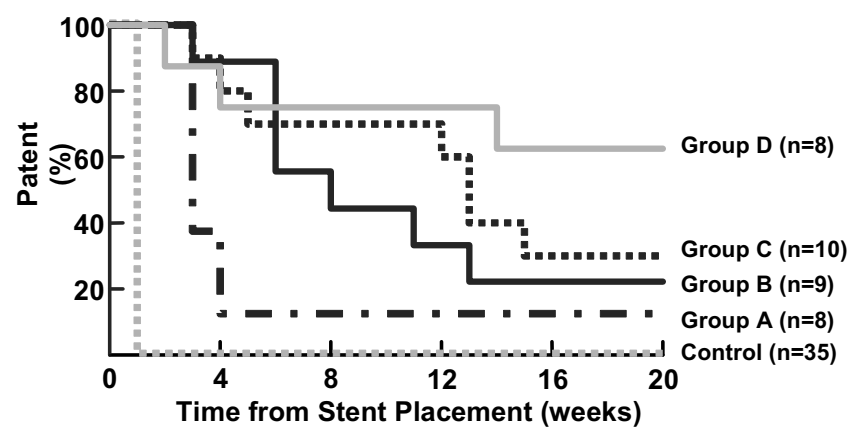

Figure 2. Kaplan-Meier freedom from stent closure, stratified by treatment group.

urea, and electrolyte laboratory blood tests. Weekly follow-up was performed up to a maximum of 20 weeks. The study had obtained animal studies ethics committee approval.

\section{Results}

Four episodes of minor and brief bleeding occurred during stent placement. These were treated with diluted topical epinephrine solution and resolved without incident. A pneumothorax developed after placement of 1 airway bypass stent. The stent was removed, and the transbronchial passage was sealed with a blood patch that clotted within the passage. The pneumothorax was treated with insertion of a chest tube, and the dog recovered well without sequelae. Leukopenia developed in $1 \mathrm{dog}$ with a white blood cell count of $4.5 \mathrm{U} \times 10^{3}$ cells $/ \mathrm{mL}$ (normal range, 6.0-17.0 $\mathrm{U} \times$ $10^{3}$ cells $/ \mathrm{mL}$ ). The white cell count level returned to a normal value within 3 days without further recurrence or clinical illness. There was no early or late mortality related to the airway bypass stents. No delayed hemorrhage or pneumothorax occurred. Control stents were all occluded at the first week of bronchoscopic follow-up. In contrast, mitomycin C-treated stents had a prolongation of stent patency, and the duration of stent patency was associated with the number of once-weekly topical mitomycin applications (Table 2; Figure 2). The median duration of stent patency in groups A, B, C, and D was 3, 8, 13, and greater than 20 weeks, respectively (Table 2; Figure 2). On the 20th week of follow-up, 5 of the 8 stents in group D were still patent. Examples of patent and occluded stents as visualized on bronchoscopy are shown in Figure 3.

\section{Discussion}

Emphysema is a common disease that affects approximately 2 million individuals in the United States and is the fourth leading cause of death. It is anatomically defined as an irreversible increase in the size of the air spaces distal to the terminal bronchioles. This increase results from the destructive activity of neutrophil and macrophage elastase. ${ }^{8}$ The loss of lung tissue alters the physical properties of the lung 

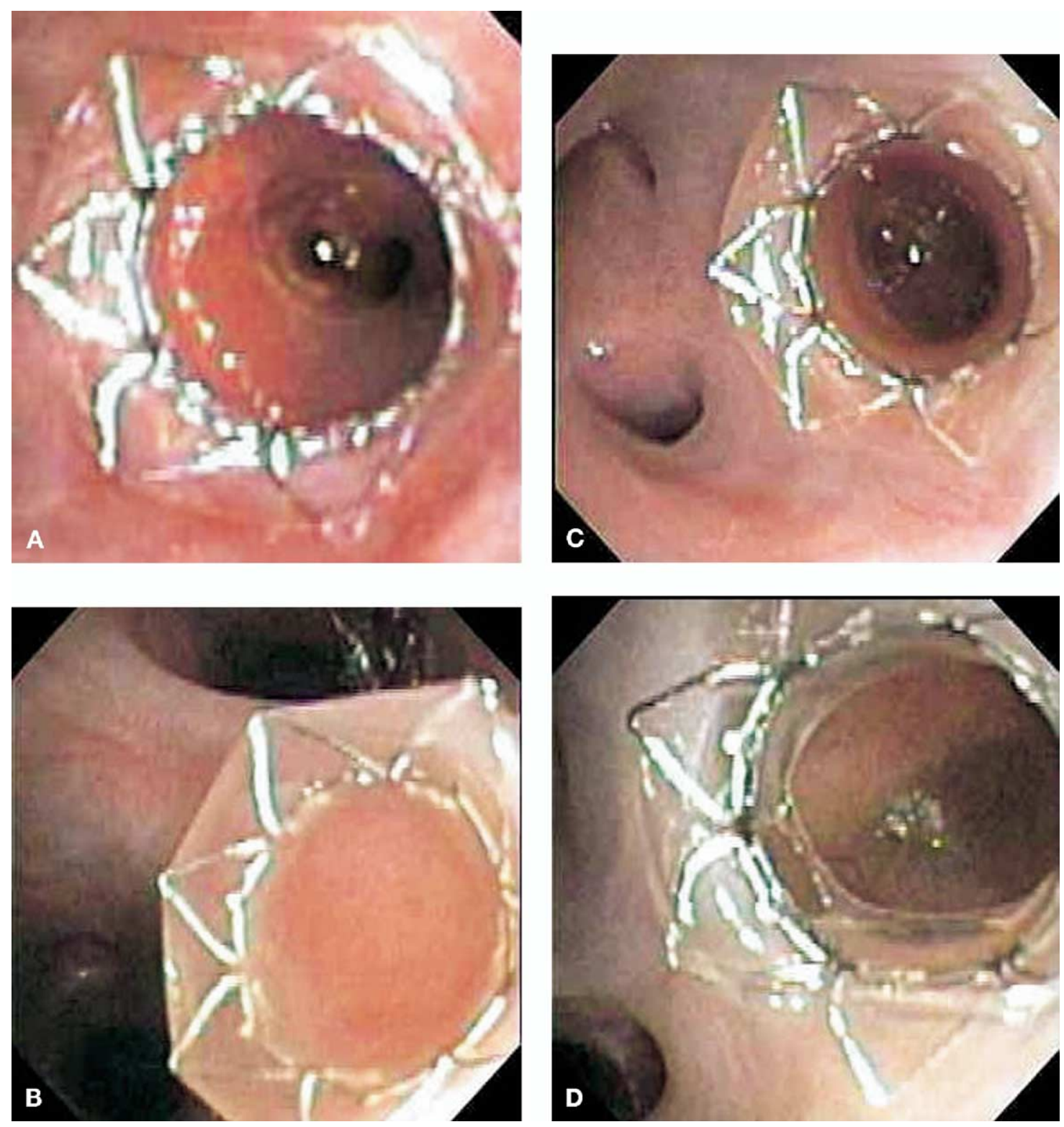

Figure 3. Examples of patent and occluded stents visualized on bronchoscopy. A, Stent at the time of placement. B, Occluded control stent at the 1-week follow-up. C, Patent mitomycin C stent at the 1-week follow-up. D, Patent mitomycin C stent at the 14-week follow-up.

and leads to a loss of lung elastic recoil and to progressive dynamic hyperinflation of the lungs. These changes result in enlargement of the thorax, flattening of the diaphragm, increased work of breathing, increased dyspnea, and reduced exercise tolerance. ${ }^{9}$ The progressive loss of elastic recoil traps the patient in a state of hyperinflation in which forced expiratory effort cannot reduce the residual volume, because the force extended to empty the lungs collapses the small airways and obstructs the outflow of gas. Progressive hyperinflation of the lungs and hyperextension of the chest wall also diminishes inspiratory capacity. To maintain ad- equate minute ventilation, the respiratory rate must increase, resulting in an increase in the work of breathing and in dyspnea. ${ }^{10}$

Surgical options in the treatment of emphysema include lung transplantation and lung volume reduction surgery. Both of these treatment modalities have specific indications, and their use is limited to selected patients. Our group embarked on an experimental study of airway bypass with the goal of developing a palliative treatment for patients with homogenous severe emphysema who are not candidates for either lung transplantation or lung volume reduc- 
tion surgery. Our group has previously demonstrated that the creation of extra-anatomic bronchopulmonary passages in ex vivo emphysematous lungs resulted in the improvement of forced expiratory flow and volume. ${ }^{5}$ The transbronchial passages created took advantage of the extensive collateral ventilation present in emphysematous lungs to allow for additional removal of trapped gas and further reduction of residual volume not obtainable through the airways. The airway bypass stent was developed as a noncollapsing structure to prevent the collapse and closure of the transbronchial passages. Crucial steps in the clinical performance of this procedure include the ability to safely place airway bypass stents transbronchially without any associated early or late morbidity. Maintenance of stent patency is also an important factor if the treatment is to become clinically useful, with potential durable benefits. Our experiment was designed to address these issues.

Our earlier experimental work used a radiofrequency device to create the transbronchial passage. ${ }^{5,11}$ This device, however, has the potential disadvantages of injuring adjacent tissues because of the radial spread of heat and of penetrating too deeply, with resultant hemorrhage or pneumothorax. The 22-gauge cytology needle was chosen in this experiment because it had the advantage of creating only a tiny transbronchial passage. Any bleeding encountered from the puncturing of a peribronchial blood vessel would be expected to be self-limited. The ability to judge the distance and control the advancement of the needle and the ability to aspirate through the needle were thought to be additional safety features of using a needle to initially form a small transbronchial track. With this technique, we did not encounter any major hemorrhage in the placement of 70 stents in 12 dogs. All 4 episodes of bleeding were minor and brief. They were treated with diluted topical epinephrine solution and resolved without incident. The balloon was used to enlarge the small transbronchial passage to allow for the placement of the stent-delivery device within the passage. The balloon was thought to provide an additional benefit in that if bleeding occurred after dilation of the tract, it could potentially be used to tamponade the bleeding. By comparison, the radiofrequency device did not have the safety features of the needle-and-balloon technique as described here. The needle-and-balloon technique, however, is associated with the disadvantages of requiring 2 separate devices and procedural steps, which could result in added complexity and prolonged time to form the transbronchial passage. In our opinion, the potential safety features of the needle-and-balloon technique outweigh those of the radiofrequency device, and the study was performed with the needle-and-balloon technique to evaluate the feasibility and safety of such a technique. A combined needle-and-balloon device has subsequently been developed to overcome the disadvantages encountered with the separate needle and balloon devices used in this study.

Mitomycin $\mathrm{C}$ is known to inhibit fibroblast proliferation and vascular ingrowth in tissues, and these properties have led to its topical use in clinical ophthalmologic surgery. In 1963, Kunitomo and colleagues ${ }^{12}$ first introduced the topical use of mitomycin $\mathrm{C}$ in the eye after pterygium surgery. Chen ${ }^{13}$ in 1983 reported the use of mitomycin $\mathrm{C}$ as adjunctive therapy in trabeculectomy surgery for glaucoma. The authors found that it reduced scarring at the scleral flap with $100 \%$ success at the relatively low dose of $0.02 \%$. A double-blinded, prospective study in 1988 helped to popularize its use in North America by showing a decrease in the pterygium recurrence rate from $88.9 \%$ to $2.3 \%$ when compared with placebo. ${ }^{14}$ The use of topical mitomycin $\mathrm{C}$ on respiratory epithelium, specifically on nasal mucosa, was first explored as adjunctive therapy in dacryocystorhinostomy. ${ }^{15}$ A recent study by Ingram and colleagues ${ }^{16}$ found it to be effective in maintaining patent maxillary antrostomy sites in a rabbit model. Electron microscopy revealed that after an initial period of ciliary loss, no permanent damage to the mucosa was noted, and there was a return of normal ciliary function within 1 week. Topical mitomycin $\mathrm{C}$ has also been reported to inhibit the formation of granulation tissue in the airway and has been found to be useful in the treatment of difficult airway stenosis. ${ }^{6}$ Its usefulness in the prevention and reduction of laryngotracheal stenosis has been shown in several animal studies. ${ }^{17-19}$ Successful clinical application of topical mitomycin $\mathrm{C}$ for the treatment of glottic and subglottic stenosis has also been reported in the otorhinolaryngology literature. ${ }^{20,21}$ On the basis of these findings, we chose to assess the effects of topical mitomycin $\mathrm{C}$ on airway bypass stent patency. Our results suggest that stent patency may be prolonged with a single topical application of mitomycin $\mathrm{C}$ and that the duration of stent patency was further prolonged in association with an increase in the number of once-weekly treatments.

The more frequently used dosage of mitomycin $\mathrm{C}$ as a chemotherapeutic agent is 10 to $20 \mathrm{mg} / \mathrm{m}^{2}$ of body-surface area and is given as a single-bolus intravenous injection. This treatment is repeated on a cycle of every 6 to 8 weeks. For a person with a body weight of $70 \mathrm{~kg}$ and surface area of $2.16 \mathrm{~m}^{2}$, a single injection of 21.6 and $43.2 \mathrm{mg}$ would correspond to a dosage of 10 and $20 \mathrm{mg} / \mathrm{m}^{2}$, respectively. Our study used only a small amount of topical mitomycin C relative to the systemic chemotherapeutic dose delivered to oncology patients. Only approximately $0.6 \mathrm{mg}$ would have been delivered topically in the treatment of 3 stents per week. In our study, we did not observe any significant local adverse effects. A transient episode of leukopenia, however, did develop in $1 \mathrm{dog}$ and it is possible that systemic absorption had occurred, with resultant mitomycin $\mathrm{C}$ toxicity and bone marrow suppression. This is certainly a possible side 
effect of topical drug application. ${ }^{22}$ Systemic absorption of mitomycin $\mathrm{C}$ and monitoring of the serum level are important issues that require further future evaluation and this is a limitation of this study. Titration to dose-response levels and assessment of toxicity need to be performed before application in humans. However, this study was primarily designed to find out whether stent patency could be prolonged by local application of an antifibrotic agent. The affirmative results suggest that a drug-eluting stent may well be worth developing. This would have the advantage of avoiding the weekly treatment schedules, which would be impractical in the clinical setting.

In summary, it was feasible and safe to perform airway bypass stent placement in vivo. In the canine model, the control stents became occluded within 1 week. Topical mitomycin $\mathrm{C}$ application, however, resulted in a prolonged duration of stent patency, and the duration of stent patency was associated with the duration of mitomycin $C$ treatment. The results confirm that the wound-healing process in response to the airway bypass stent can be suppressed by topical application of anti-inflammatory or antifibrotic agents.

We thank Patricia Toeniskoetter, Naomi Still, and Katheryn Cook for their technical assistance.

\section{References}

1. Van Allen CM, Lindskog GE, Richter HT. Gaseous interchange between adjacent lung lobules. Yale J Biol Med. 1930;2:297-300.

2. Hogg JC, Macklem PT, Thurlbeck WM. The resistance of collateral channels in excised human lungs. J Clin Invest. 1969;48:421-31.

3. Terry PB, Traystman RJ, Newball HH, Batra G, Menkes HA. Collateral ventilation in man. $N$ Engl J Med. 1978;298:10-5.

4. Macklem PT. Collateral ventilation [editorial]. N Engl J Med. 1978; 298:49-50.

5. Lausberg HF, Chino K, Patterson GA, Meyers BF, Toeniskoetter PD, Cooper JD. Bronchial fenestration improves expiratory flow in emphysematous human lungs. Ann Thorac Surg. 2003;75:393-8.

6. Erard AC, Monnier P, Spiloupoulos A, Nicod L. Mitomycin C for control of recurrent bronchial stenosis. Chest. 2001;120:2103-5.

7. Correa AJ, Reinisch L, Sanders DL, et al. Inhibition of subglottic stenosis with mitomycin C in the canine model. Ann Otol Rhinol Laryngol. 1999;108:1053-60.

8. Snider G, Kleinerman J, Thurlbeck W, et al. The definition of emphysema. Report of a National Heart, Lung, and Blood Institute, Division of Lung Disease Workshop. Am Rev Respir Dis. 1985;132:182-5.

9. Rochester D, Braun N, Arora N. Respiratory muscle strength in chronic obstructive pulmonary disease. Am Rev Respir Dis. 1979;119: 151-4.

10. Sharp J, Danon J, Druz W, et al. Respiratory muscle function in patients with chronic obstructive pulmonary disease: its relationship to disability and to respiratory therapy. Am Rev Respir Dis. 1974;110: 154-67.

11. Rendina EA, De Giacomo T, Venuta F, Coloni GF, Meyers BF, Patterson GA, et al. Feasibility and safety of the airway bypass procedure for patients with emphysema. J Thorac Cardiovasc Surg. 2003;152:1294-9.

12. Kunitomo N, Mori S. Studies on the pterygium. Part IV. A treatment of the pterygium by mitomycin-C instillation. Nippon Ganka Gakkai Zasshi. 1963;67:601-7.

13. Chen $\mathrm{CW}$. Enhanced intraocular pressure controlling effectiveness of trabeculectomy by local application of mitomycin-C. Trans Asia Pacif Acad Ophthalmol. 1983;9:172-7.
14. Singh G, Wilson MR, Foster CS. Mitomycin eye drops as treatment for pterygium. Ophthalmology. 1988;95:813-21.

15. Kao SCS, Liao CL, Tseng JHS, Chen MS, Hou PK. Dacryocystorhinostomy with intraoperative mitomycin-C. Ophthalmology. 1997;104: 86-91.

16. Ingram DR, Volk MS, Biesman BS, Pankratov MM, Shapshay SM. Sinus surgery: does mitomycin-C reduce stenosis? Laryngoscope. 1998;108:883-6.

17. Coppit G, Perkins J, Munaretto J, et al. The effects of mitomycin-C and stenting on airway wound healing after laryngotracheal reconstruction in a pig model. Int J Pediatr Otorhinolaryngol. 2000;53:125-35.

18. Eliashar R, Eliachar I, Esclamado R, et al. Can topical mitomycin prevent laryngotracheal stenosis? Laryngoscope. 1999;109:1594-600.

19. Spector JE, Werkhaven JA, Spector NC, et al. Preservation of function and histologic appearance in the injured glottis with topical mitomycin-C. Laryngoscope. 1999;109:1125-9.

20. Rahbar R, Valdez TA, Shapshay SM. Preliminary results of intraoperative mitomycin- $\mathrm{C}$ in the treatment and prevention of glottic and subglottic stenosis. J Voice. 2000;14:282-6.

21. Ward RF, April MM. Mitomycin-C in the treatment of tracheal cicatrix after tracheal reconstruction. Int J Pediatr Otorhinolaryngol. 1998;44: 221-6.

22. Ferguson MK. The effect of antineoplastic agents on wound healing. Surg Gynecol Obstet. 1982;154:421-9.

\section{Discussion}

Dr Scott J. Swanson (New York, NY). Your paper is quite interesting. Do you know where the distal end of your stent sits? Have you ever done bronchography or a computed tomographic scan to look at this?

Dr Choong. The stents go through the transbronchial wall into the lung parenchyma, and because we're using normal research dogs, the passage creation goes straight into solid lung parenchyma. We have, however, tried this on explanted transplant recipient emphysematous lungs, as well as in patients before either lobectomy or pneumonectomy, and we have observed that the transbronchial passage goes straight into emphysematous lung. We have a video clip if you would like to have a quick look for this discussion that demonstrates the passage into human emphysematous lungs.

Dr Swanson. Do you have any plans for human trials with this?

Dr Choong. In the future we do. This is, however, only a preliminary study just to assess the effects of topical mitomycin. Obviously, weekly application of topical mitomycin is not practical. Therefore, the principle behind this study was to evaluate whether it was feasible and safe to use topical mitomycin and then subsequently to consider developing a drug-eluting stent for consideration in human application.

Dr Sudish Murthy (Cleveland, Ohio). Congratulations, Cliff. It's a very provocative study. We have been relatively disappointed with the use of topical mitomycin to maintain larger airway stent patency. I'm just wondering if the passage of that delivery catheter once a week is enough to dilate these stents and maintain patency. It looked like you were inserting the delivery catheter through the stent, and I'm just wondering if this isn't an epiphenomenon of the mitomycin instillation, since that wasn't done in control cases.

Dr Choong. The catheter was just used to deliver the topical mitomycin. We do not place the catheter through the stent into the passage or the lung itself.

Dr Walter Weder (Zurich, Switzerland). Have you seen local necrosis or other local toxicity in the repeated group? 
Dr Choong. We have not seen any significant local adverse effects from the topical mitomycin. I think that may be most likely due to the low concentration and low dose that we're using.

Dr Thomas M. Egan (Chapel Hill, NC). That was a very nicely presented piece of work and very interesting. Your group has some experience with emphysematous dogs, as I recall. Are the patency rates of these stents any better in dogs with emphysema?
Dr Choong. We have not used these stents in any of the emphysematous dogs.

Dr Egan. The next question is - and your data beg the question-have you any experience with drug-eluting stents, such as rapamycin-eluting stents?

Dr Choong. We have looked into that previously just as a preliminary evaluation, and the results have not been as good as using repeated weekly topical mitomycin. 